\title{
Emission permits trading and downstream strategic market interaction
}

\author{
Giuseppe de Feo, Joana Resende’, María Eugenia Sanin ${ }^{\ddagger}$
}

January 2012

\begin{abstract}
This paper contributes to the debate on "windfall" profits in oligopolies subject to environmental regulation based on tradable emission permits. We propose a model of upstream-downstream strategic competition, in which the upstream market corresponds to the permits market and the downstream market corresponds to the output market. We assume that a leader in the permits market is able to set the price of permits, while in the output market we introduce strategic interaction by assuming Cournot competition. This model allows us to account for the effects of the technological linkages between the permits and the output market, showing that strategic interaction in the output market may give rise to an additional source of distortion in the permits market. In particular, strategic interaction in the output market endows both firms with incentives to adopt "rival's cost-raising strategies" in the permits market: both firms (including the follower) try to take advantage of permits trading to reduce their abatement needs and become more competitive on the output market. As a result, all the firms, including the price-making firm and irrespective of the fact that it is a buyer or a seller, abate less than required by efficiency as the price of permits is always higher than firms' marginal abatement cost.
\end{abstract}

\footnotetext{
${ }^{*}$ Department of Economics, University of Strathclyde; and Dipartimento di Scienze Economiche e Aziendali, Università degli Studi di Pavia. E-mail: giuseppe.defeo@strath.ac.uk

${ }^{\dagger}$ University of Porto and Cef.up. E-mail: jresende@fep.up.pt. Financial support from FCT is deeply acknowledged (Research grant PTDC/EGE-ECO/115625/2009).

${ }^{\ddagger}$ LAMETA, University of Montpellier 1 and École Polytechnique, Paris. E-mail: mariaeugenia.sanin@polytechnique.edu
} 


\section{Introduction}

The discussion on "windfall" profits in oligopolies subject to environmental regulation based on tradable emissions permits (TEP) has inspired many theoretical papers ${ }^{1}$. Most of them, surveyed in Montero (2009), model market power in the TEP market alone, either considering the related output market as competitive or completely avoiding its modeling. A particular strand of this literature wishes to understand the interaction between the TEP and the output market. Relying on a dominant-fringe setting they find that a firm that dominates both in the permits and in the output markets is able to manipulate the permit price to increase its profits both in the market for permits (as in Hahn, 1985) and in the output market ${ }^{2}$ (see Misolek and Elder, 1989; Eshel, 2005). ${ }^{3}$ In this paper we move away from the dominant-fringe paradigm to study how strategic interaction $\grave{a}$ la Cournot in a duopolistic output market may affect the outcome on the TEP market. To do so we consider a first mover in the permits market that competes with a second mover that is also its competitor in the output market. We find the previous exercise fruitful since, differently from the dominant-fringe literature, we show that the follower in the permits market does not behave as a typical price-taker, exerting some influence on the equilibrium price of permits. Additionally we find that differently from Eshel (2005), the dominant firm in the permits market fixes a permits price above its marginal abatement costs, even when it is a net buyer of permits. Our results underline the importance of taking into account the specific market structure of the output market subject to the TEP regulation in order to predict the effect of such regulation on competition and on consumer surplus.

As underlined by Montero (2009), a formal empirical test of market power in tradable permit markets, i.e. a test comparing prices and marginal abatement costs, has not been performed for any of the (local or regional) TEP markets implemented so far. Such a test would imply estimating marginal abatement cost curves and then comparing them with observed permits prices. ${ }^{4}$ Instead, several experimental papers have been published on the issue: Godby (2002) tests Hahn (1985) and Misiolek and Elder (1989), finding that these settings predict

\footnotetext{
${ }^{1} \mathrm{~A}$ famous example is the permits for ozone-depleting chemicals created in the United States in the late 80 's, where billions of dollars worth of profits were created for seven major CFCs/halon producers. Later U.S. Congress imposed a tax to absorb this revenue (Tietenberg, 2006).

${ }^{2}$ Fehr (1993) and Sartzetakis (1997) have also considered strategic interaction in the output market but their objective is to focus on monopolization or excessive entry barriers instead of assessing the effects of strategic interaction on permits prices. In fact, Fehr (1993) assumes that downstream firms buy permits for a given supply, whereas Sartzetakis (1997) assumes a competitive permits market.

${ }^{3}$ Fehr (1993) extends the analysis to the case of two dominant firms and a fringe competing in quantities but focusing on exclusionary manipulation.

${ }^{4}$ If such an empirical test existed, the predictions of this paper could be tested by studying the interaction between those measures of market power in the permits market and the degree of market power associated with downstream market structure.
} 
market outcomes better than the perfectly competitive assumption and that the impact of market power on efficiency may be significant. Brown-Kruse et al. (1995) also design a dominant-fringe experiment, finding results in line with the previous paper. ${ }^{5}$

Filling the existing gap between theoretical and empirical studies, Chen and Hobbs (2005) simulate the interaction of a pollution permits market with an electricity market. In their case, market power in the energy market is modeled using a Cournot game, while a conjectured price response model is used in the permits market. An illustrative application is conducted on the Pennsylvania-New Jersey-Maryland electricity market (PJM) and the USEPA Ozone Transport Commission NOx Budget Program. Their results show that simulated solutions of Cournot competition are a good approximation to actual prices of electricity during the year 2000 and that the NOx market influences the Cournot energy market. In particular, they find that a high concentration in the market for permits can exacerbate the effects of market power in energy markets. ${ }^{6}$

Finally, some facts may raise some concern on the possible existence of market power in TEP markets: (i) in the case of the interaction between the NOx permits market and the electricity market in California, firms shown to exert market power in electricity (Wolak, 2003) were allocated $56 \%$ of total initial stock of permits, and; (ii) in the case of the interaction between the permits market created by the NOx Budget Program and the PJM electricity market, $90 \%$ of emissions in the NOx budget program came from the six larger electricity generators in the PJM. ${ }^{7}$ Similarly, in the European context, the existing empirical evidence suggests that the risk of market power in a tradable permits market covering more than one sector, like the EU-ETS (EU Emission Trading Scheme), seems smaller than in the case where only one oligopolistic sector is included ${ }^{8}$ or in the case where one oligopolistic sector represents a big portion of the total permits market.

This paper wishes to contribute to the literature on non-competitive emissions trading by accounting for an oligopolistic downstream market and discussing how its characteristics determine firms' trading strategies in the permits market. To this end, we model the interaction between the tradable emissions permits market (upstream) and the output market (downstream) by considering the following three-stage game: in the first stage, one of the firms sets the price of permits alone; in the second stage permits are traded; and, finally, in the third stage, firms compete $\grave{a}$ la Cournot in the output market. Our model follows Montero (2002) and the traditional theory on upstream-downstream interaction (from Salinger, 1988

\footnotetext{
${ }^{5}$ For a survey of the first experimental papers on TEP see Mestelman and Muller (1997).

${ }^{6}$ In contrast, in our paper, we look at the effect of strategic interaction in the output market on the outcomes in the permits market.

${ }^{7}$ Its Herfindahl-Hirschman Index was 0.154.

${ }^{8}$ Linares et al. (2006) argue that electricity generators represent more than $50 \%$ of emissions covered by the EU-ETS market.
} 
to Ordover, Salop and Saloner, 1990), assuming that the upstream (permits) market is cleared before strategic interaction in the output market. However, unlike the latter papers, our model allows firms' position in the upstream market (buyer or seller of permits) to be endogenous. Our assumption regarding the fact that a firm moves first in the permits market captures the fact that the majority of the permits markets created so far have been organized in sequential "phases": in a first phase, only the most polluting firms receive tradable permits that can be traded in the permits market, whereas their less polluting competitors are only included in a second phase (usually two to four years latter). This was the case in the EU-ETS, in the US Acid Rain Market and in the NOx budget program, among many others. In this respect, Boemare and Quirion (2002) note that in the EU-ETS there is no provision for voluntary "opt in" by firms below the threshold size that assigned firms to the first phase. They argue that such "opt in" provisions could help dilute any emerging market power.

In the context of our model, we were able to identify three potential channels of market distortions associated with environmental regulation based on tradable emission permits. The first market distortion is due to market power in the permits market. Everything else the same, as in Hahn (1985), the first mover in the permits market manipulates the price of permits to reduce its own pollution abatement costs. The other market distortions are related to firms' market power in the output market, which gives both firms an incentive to under-invest in pollution abatement. By using permits for production, firms become more competitive in the output market as they reduce their own marginal abatement costs, while increasing their rival's marginal abatement costs. Differently from the dominant-fringe literature's findings, we show how strategic interaction in the output market induces the follower in the permits market to adopt rival's cost-raising strategies as well. ${ }^{9}$

The rest of the paper is organized as follows. Section 2 presents the basic setup. Section 3 characterizes the Subgame Perfect Nash Equilibrium of our game. Section 4 compares our equilibrium outcomes with a benchmark case without strategic interaction in the output market. Finally, Section 5 concludes.

\section{Basic setup}

Consider two firms $(i$ and $j$ ) that produce a homogeneous good, whose inverse demand function is given by $p=\max \left[1-y_{i}-y_{j}, 0\right]$. Denote by $p$ the price of the good and by $y_{k}$ the quantity of the good produced by firm $k=i, j$. The total output production is denoted by $y=y_{i}+y_{j}$. We assume that the two firms have identical production costs and, for simplicity, we set them equal

\footnotetext{
${ }^{9}$ It is worth noting that the conclusions driven in this paper are only concerned with tradable emissions permits regulation and cannot be extrapolated to other environmental regulation instruments like taxes or standards.
} 
to zero. ${ }^{10}$ The production of goods $i$ and $j$ generates polluting emissions as a by-product. We consider that the total amount of pollution emitted during the production of $y_{k}$ is equal to $y_{k}$, i.e. the intensity of pollution is equal to 1 .

Firms are subject to environmental regulation based on a cap and trade system. Under such environmental regulation, each firm must hold a number of permits $E_{k}$ equal to the amount of non abated pollution. This regulation creates a scarce input: the tradable permits, which are available up to the cap $S$. The total stock of permits $S<\frac{2}{3}$ is allocated for free between firms. ${ }^{11}$ A percentage $\alpha$ is allocated to firm $i$ and a percentage $1-\alpha$ is allocated to firm $j$. The percentage $\alpha \in[0,1]$ and the cap $S$ are exogenously chosen by the regulator, according to the pollution control target. In a framework where only polluting firms trade these permits, the regulator's decisions regarding the allocation of permits between firms $\alpha$ and the decision regarding the total cap on emissions $S$ can be analyzed independently (Eshel, $2005) .^{12}$

When the permits received by each firm, $\alpha S$ and $(1-\alpha) S$ respectively, do not coincide with the emissions generated by the production of the optimal output quantity $y_{k}^{*}$, firms choose either to abate some of these emissions or to engage in permits trading. That is,

$$
\begin{aligned}
& E_{i}=\alpha S+x_{i} \geq 0, \\
& E_{j}=(1-\alpha) S+x_{j} \geq 0, \\
& a_{k}=y_{k}-E_{k} \geq 0, k=i, j,
\end{aligned}
$$

where $x_{k}$ denotes the amount of permits bought (when $x_{k}>0$ ) or sold (when $x_{k}<0$ ) by firm $k$, and $a_{k}$ stands for the level of emissions abated by firm $k$. Abatement of polluting emissions is costly. To abate $a_{k}$ polluting emissions, firm $k$ has a convex abatement cost function that

\footnotetext{
${ }^{10}$ On the one hand, this assumption ensures an interior equilibrium in the output market. On the other hand, the assumption allows us to avoid interferences of production costs with our analysis of firms' differences regarding their abatement technologies. The qualitative nature of equilibrium results remains valid as long as we consider firms with identical cost functions (and no fixed-costs).

${ }^{11}$ Note that in the Cournot equilibrium without environmental regulation, $y_{i}^{*}=y_{j}^{*}=\frac{1}{3}$, with $y^{*}=\frac{2}{3}$. The total amount of polluting emissions is therefore equal to $\frac{2}{3}$ (as we normalize the pollution intensity to 1 ). In this context, if the regulator fixes a cap $S$ higher than $\frac{2}{3}$, the cap is not binding and the regulation has no pollution reduction effect.

${ }^{12}$ The cap on pollution is generally fixed by the regulatory authority with the help of experts -like the IPCC 1990 Scientific Assessment in the case of the Kyoto protocol (Houghton et al., 1990) and its European side agreement for the creation of the EU-ETS- who state the impacts of pollution and the pollution reduction required to diminish those impacts to an acceptable level. By creating property rights for an amount equal to the acceptable environmental damage, the authority tries to restore efficiency in the presence of the environmental externality, that is to achieve a market equilibrium where the marginal cost of pollution reduction (i.e. the property right's price) equals the marginal benefit of such reduction (i.e. the unit improvement in environmental quality).
} 
is separable from the production cost and is given by $\frac{\gamma_{k}}{2} a_{k}^{2}$, with a marginal abatement cost (MAC) equal to $\gamma_{k} a_{k}$.

Under this regulatory framework, firms interact in two markets: the permits market and the output market. In the output market, both firms exert market power. In the permits market, we assume that the degree of market power is asymmetric: firm $j$ moves first in the permits market and it has the most efficient abatement technology. In particular, we set $\gamma_{j}=1$ and $\gamma_{i}>1$ in order to keep the analysis as simple as possible.

To model firms' interaction, we rely on a game theoretical approach. We propose a sequential game, in which the players are the two firms, and the timing is the following: in the first stage, firm $j$ sets alone the price of permits $(q)$; in the second stage, firm $i$ observes the price of permits posted by firm $j$ and chooses the amount of permits to buy in the permits market $\left(x_{i}\right)$. Firm $j$ must always clear the permits market, with $x_{j}=-x_{i}$. Finally, in the third stage, given firms' after-trade amount of permits available $\left(E_{i}\right)$, firms simultaneously interact in the output market strategically competing on quantities $\left(y_{i}\right.$ and $\left.y_{j}\right)$. The payoffs are firms' profits and strategies are $q \in \mathbb{R}^{+}, x_{i} \in[-S \alpha, S-\alpha S]$ and $y_{k} \in \mathbb{R}^{+}$.

\section{Characterization of the equilibrium}

We rely on the notion of subgame perfect Nash equilibrium (SPNE) to investigate firms' optimal behavior.

Definition 1 A SPNE corresponds to a vector of strategies

$$
\left(q^{*}, x_{i}^{*}(q), y_{i}^{*}\left(q, x_{i}\right), y_{j}^{*}\left(q, x_{i}\right)\right)
$$

such that

(i) For any given $q$ and $x_{i}, y_{i}^{*}$ is the best response of firm $i$ to $y_{j}$ and vice-versa;

(ii) For any given $q, x_{i}^{*}(q)$ maximizes firm $i^{\prime} s$ profits when firm $i$ anti-cipates $y_{k}^{*}\left(q, x_{i}\right)$,

(iii) $q^{*}$ maximizes the total profits of firm $j$, when firm $j$ anticipates $y_{k}^{*}\left(q, x_{i}\right)$ and $x_{i}^{*}(q)$.

Definition 2 Firms' total profits are given by

$$
\begin{aligned}
\Pi_{i}\left(q, x_{i}, y_{i}, y_{j}\right) & =y_{i} p\left(y_{i}, y_{j}\right)-c_{i}\left(y_{i}\right)-q x_{i}-\frac{\gamma_{i}}{2}\left(y_{i}-x_{i}-\alpha S\right)^{2}, \\
\Pi_{j}\left(q, x_{i}, y_{i}, y_{j}\right) & =y_{j} p\left(y_{i}, y_{j}\right)-c_{j}\left(y_{j}\right)+q x_{i}-\frac{1}{2}\left[y_{j}+x_{i}-(1-\alpha) S\right]^{2},
\end{aligned}
$$

where, as explained above, we assume $c_{i}\left(y_{i}\right)=c_{j}\left(y_{j}\right)=0$.

Given this payoff specification, we rely on backward induction techniques to compute the SPNE of the game. 


\subsection{Output market interaction}

In the third stage, once the permits markets is cleared, firms compete $\grave{a}$ la Cournot in the output market. Given $q$ and $x_{i}(q)$, firms simultaneously solve the following optimization problems:

$$
\begin{aligned}
& \max _{y_{i} \geq 0} \Pi_{i}\left(q, x_{i}, y_{i}, y_{j}\right), \\
& \max _{y_{j} \geq 0} \Pi_{j}\left(q, x_{i}, y_{i}, y_{j}\right),
\end{aligned}
$$

The solution to the optimization problems (3) and (4) respectively define firm $i$ and firm $j^{\prime} s$ reaction functions:

$$
\begin{aligned}
y_{i}^{*}\left(y_{j}, x_{i}\right) & =\max \left[\frac{1-y_{j}+\gamma_{i} x_{i}+S \alpha \gamma_{i}}{\gamma_{i}+2}, 0\right] \\
y_{j}^{*}\left(y_{j}, x_{i}\right) & =\max \left[\frac{S(1-\alpha)+1-y_{i}-x_{i}}{3}, 0\right] .
\end{aligned}
$$

Note that as the marginal costs are zero for $y_{k}=0$, we always have $\left.\frac{\partial \Pi_{k}\left(q, x_{i}, y_{i}, y_{j}\right)}{\partial y_{k}}\right\rceil_{y_{k}=0}>$ $0 \forall k=i, j$. This result together with the second order conditions (concavity of the profit function) guarantees an interior solution, with $y_{i}^{*}>0$ and $y_{k}^{*}>0$.

Accordingly, in the equilibrium of the third stage (5) and (6) must hold simultaneously. We observe that, for given outcomes in the permits market and rival's output choice, each firm chooses the equilibrium output level $y_{k}^{*}\left(x_{i}\right)$ for which there is a perfect balance between the marginal revenue and the marginal cost (including abatement marginal costs), yielding the following equilibrium output levels:

$$
\begin{aligned}
y_{i}^{*}\left(x_{i}\right) & =\frac{\left(3 \gamma_{i}+1\right)\left(x_{i}+S \alpha\right)+2-S}{3 \gamma_{i}+5}, \\
y_{j}^{*}\left(x_{i}\right) & =\frac{S\left(\gamma_{i}+2\right)+\left(\gamma_{i}+1\right)\left(1-2\left(x_{i}+S \alpha\right)\right)}{3 \gamma_{i}+5},
\end{aligned}
$$

with $p^{*}\left(x_{i}\right)=1-y_{i}^{*}\left(x_{i}\right)-y_{j}^{*}\left(x_{i}\right)>0$, since $y_{i}^{*}\left(x_{i}\right)+y_{j}^{*}\left(x_{i}\right)<1 \forall x_{i} \in(-\alpha S, S-\alpha S)$ because the highest possible total production in equilibrium (obtained in a Cournot market with no costs and no environmental restrictions) is $2 / 3$.

The expressions (7) and (8) show how outcomes in the permits markets affect output equilibrium decisions through marginal abatement costs, with

$$
\frac{\partial y_{i}^{*}\left(x_{i}\right)}{\partial x_{i}}=\frac{3 \gamma_{i}+1}{3 \gamma_{i}+5}>0 \text { and } \frac{\partial y_{j}^{*}\left(x_{i}\right)}{\partial x_{i}}=-2 \frac{\gamma_{i}+1}{3 \gamma_{i}+5}<0 .
$$

Similarly, by changing variable $x_{i}$ in (1) and (2), with $x_{i}=E_{i}-\alpha S$, we can study the cross-partial derivatives $\frac{\partial^{2} \Pi_{i}}{\partial y_{i} \partial E_{i}}$ and $\frac{\partial^{2} \Pi_{j}}{\partial y_{j} \partial E_{i}}$ (supermodularity or complementarity, see Amir, 
2005 for definitions). This allows us to show that the larger $E_{i}$, the larger the equilibrium output of firm $i$ and the smaller the equilibrium output of firm $j$. Accordingly, the larger the amount of permits used for production by firm $k$, the lower its abatement needs $a_{k}$, the lower its marginal abatement costs, and therefore, the higher its output production. This direct effect is reinforced by strategic substitutability of firms' output decisions (since firms compete à la Cournot). ${ }^{13}$

\subsection{Demand/supply of permits by the follower}

In the second stage, the choice of firm $i$ about the amount of permits to buy from/sell to firm $j$ maximizes its profits given the price of permits $q$ set in the first stage. When deciding $x_{i}(q)$, firm $i$ anticipates the equilibrium in the Cournot game at the following stage. Accordingly, the choice of firm $i$ about permits trading $x_{i}(q)$ not only takes into account the marginal profitability of permits transactions but also the impact of permits trading in the output market outcome, through $y_{i}^{*}\left(x_{i}\right)$ and $y_{j}^{*}\left(x_{i}\right)$.

Analytically, in the second stage, firm $i$, solves the following optimization problem:

$$
\begin{aligned}
& \max _{x_{i}} \Pi_{i}\left(q, x_{i}, y_{i}^{*}\left(x_{i}\right), y_{j}^{*}\left(x_{i}\right)\right) \\
& \text { s.t. } x_{i} \in[-\alpha S, S-\alpha S] .
\end{aligned}
$$

The solution to problem (9) defines the equilibrium level of permits trading conditional on the price of permits, $x_{i}^{*}(q)$. The choice of $x_{i}$ will then determine the amount of permits to use in production $E_{i}^{*}(q)=\alpha S+x_{i}^{*}(q)$ and firms' abatement needs:

$$
\begin{aligned}
& a_{i}^{*}(q)=y_{i}^{*}\left(x_{i}^{*}(q)\right)-x_{i}^{*}(q)-\alpha S \\
& a_{j}^{*}(q)=y_{j}^{*}\left(x_{i}^{*}(q)\right)+x_{i}^{*}(q)-(1-\alpha) S .
\end{aligned}
$$

where $y_{k}^{*}\left(x_{i}^{*}(q)\right)$ is obtained by plugging $x_{i}=x_{i}^{*}(q)$ in equations (7) and (8).

In this context, the demand of permits by firm $i$ in the second stage is given by the argmax of problem (9). When this argmax corresponds to an interior solution $x_{i}^{*}(q) \in(-\alpha S, S-\alpha S)$, the closed form solution for the demand of permits can be obtained directly from the first order conditions associated to problem $(9), \frac{\partial \Pi_{i}\left(q, x_{i}, y_{i}^{*}\left(x_{i}\right), y_{j}^{*}\left(x_{i}\right)\right)}{\partial x_{i}}=0$, yielding:

$$
x_{i}^{*, i n t}(q)=\frac{3(2(1-S \alpha)-S) \gamma_{i}^{2}+(7(2-S)-12 S \alpha) \gamma_{i}+2(2-S(1-\alpha))-\left(3 \gamma_{i}+5\right)^{2} q}{6 \gamma_{i}^{2}+12 \gamma_{i}-2},
$$

as the second order condition $\frac{\partial^{2} \Pi_{i}\left(q, x_{i}, y_{i}^{*}\left(x_{i}\right), y_{j}^{*}\left(x_{i}\right)\right)}{\partial x_{i}^{2}}<0$ always holds for $\gamma_{i}>1$.

\footnotetext{
${ }^{13}$ Note that this transmission mechanism is independent of which of the two rival firms is the most efficient in terms of abatement.
} 
In the interior equilibrium, any variation in the profits from permits transactions caused by a marginal variation of $x_{i}$ is perfectly offset by an equivalent variation in output profits, whose transmission mechanism lies on $y_{i}^{*}\left(x_{i}\right)$ and $y_{j}^{*}\left(x_{i}\right)$.

The following figure illustrates the configuration of the demand/supply of permits for $S=0.3, \alpha=\frac{1}{3}$. The demand function is depicted for three values of $\gamma_{i}$. The full line represents the permits demand function for $\gamma_{i}=1$. The thick dashed line represents the demand of permits for $\gamma_{i}=2$ and finally, the thin dashed line is for $\gamma_{i}=3$.

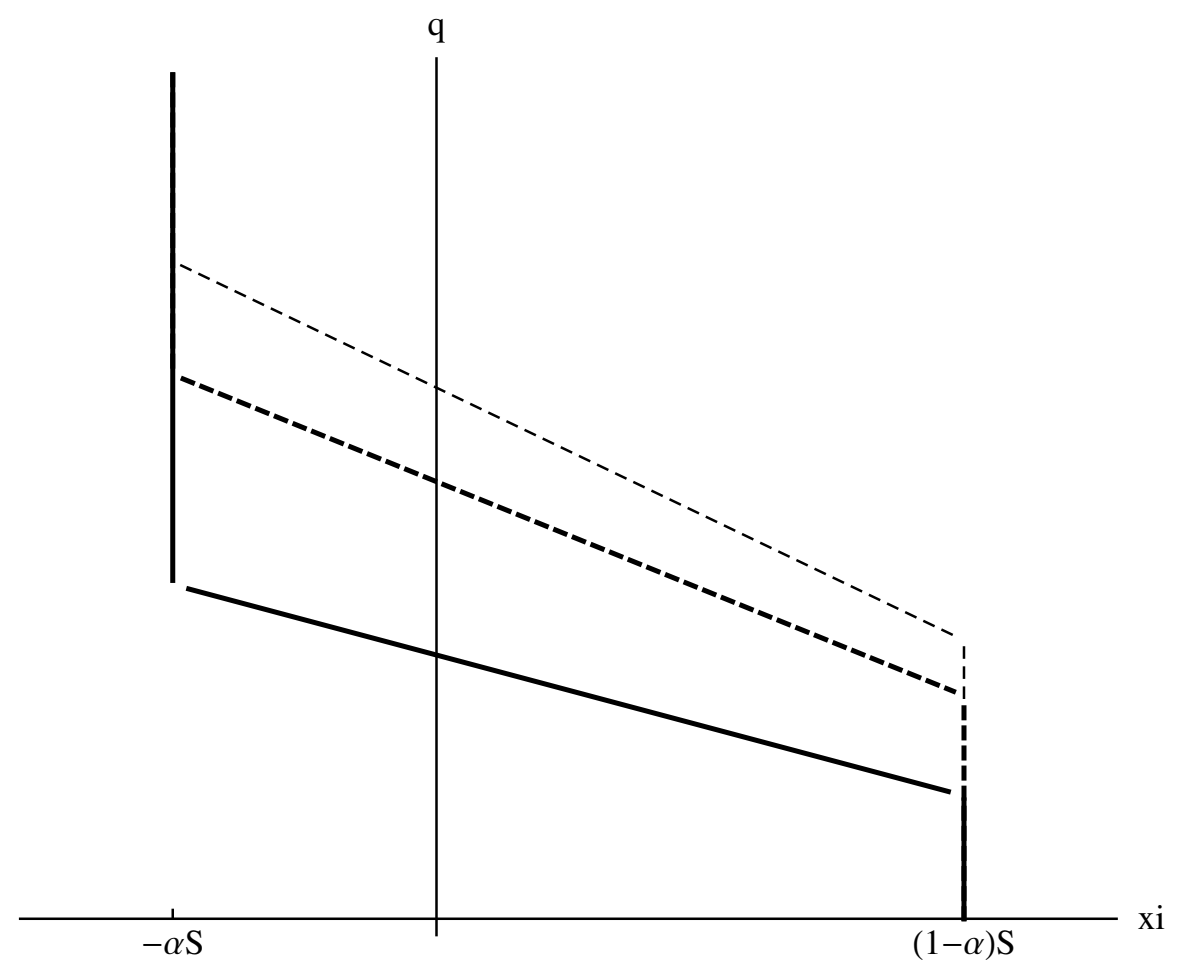

Figure 1: Firm $i$ 's demand of permits.

Figure 1 shows that, as expected, everything else the same, in an interior second stage equilibrium, when firm $i$ is a net buyer of permits (i.e. $x_{i}^{* \text { int }}(q)>0$ ), we observe that as the price of permits decreases, firm $i$ is interested in buying more permits, since $\frac{\partial x_{i}^{*, i n t}(q)}{\partial q}=$ $-\frac{\left(3 \gamma_{i}+5\right)^{2}}{6 \gamma_{i}^{2}+12 \gamma_{i}-2}<0$, for $\gamma_{i}>1$. When firm $i$ is a net seller of permits $\left(i . e . x_{i}^{*, i n t}(q)<0\right)$, as the price of permits decreases, firm $i$ is interested in supplying less permits, since $\frac{\partial x_{i}^{*, i n t}(q)}{\partial q}<0$ for $\gamma_{i}>1$. When the price of permits is so high that the entire initial stock of permits is sold by firm $i$ (corner solution, with $x_{i}^{*}=-\alpha S$ ) the demand is insensitive to price variations. Similarly, when the price of permits is so low that firm $i$ buys the entire initial stock of permits from 
firm $j$ (corner solution, with $x_{i}^{*}=(1-\alpha) S$ ), the supply of permits is also perfectly rigid. ${ }^{14}$

The following Lemma describes the type of equilibrium in the second stage for different levels of permits' price.

Lemma 3 When the permits price is lower than $\underline{q}=\frac{(6-9 S) \gamma_{i}^{2}+(14-19 S) \gamma_{i}+4}{\left(3 \gamma_{i}+5\right)^{2}}$, firm $i$ will buy all the permits initially allocated to firm $j$ and a corner solution arises, with $x_{i}^{*}(q)=S-\alpha S$. When the price of permits is higher than $\bar{q}=\frac{\left(\gamma_{i}+2\right)\left(3 \gamma_{i}+1\right)(2-S)}{\left(3 \gamma_{i}+5\right)^{2}}$, firm $i$ will sell all the permits she had received from the regulator and a corner solution arises, with $x_{i}^{*}(q)=-\alpha S$. Finally, when the price of permits is such that $q<q<\bar{q}$, an interior equilibrium arises in the second stage, with $x_{i}^{*}(q)$ equal to (10).

Proof. See the Appendix.

Proposition 4 In the second stage equilibrium, provided that the price of permits set by firm $j$ is above $\frac{2 \gamma_{i}-5 S \gamma_{i}}{3 \gamma_{i}+5}$, firm $i$ always abates less than efficiently as the the price of permits is always larger than firm $i^{\prime} s$ equilibrium marginal abatement cost $\left(q>\gamma_{i} a_{i}^{*}\right)$.

Proof. See the Appendix.

According to Proposition 1, as long as the price of permits is sufficiently high, ${ }^{15}$ in a scenario of Cournot competition in the output market, abatement decisions of the pricetaking firm in the permits market are such that its marginal abatement cost $\left(\mathrm{MAC}_{i}\right)$ is lower than the price of permits in equilibrium: despite being a follower in the permits market firm $i$ always abates less than what a firm without market power in the output market would abate in equilibrium (see Eshel, 2005), being able to increase its rival marginal costs (since the rival is responsible for clearing the permits market). The previous result would not change if we had assumed that the first-mover in the permits market $j$ chooses quantities (i.e. abatement) instead of prices in the permits market. ${ }^{16}$

When the price of permits is so low that firm $i$ buys all the permits that were allocated to firm $j$ (corner solution), in some cases it is possible to observe a price of permits that is lower

\footnotetext{
${ }^{14}$ The figure also suggests that the demand of permits shifts upwards as the degree of asymmetry between firms' abatement technologies increases. In fact, given $\gamma_{j}=1$, from the figure it follows that as $\gamma_{i}$ increases (i.e. firm $i$ becomes more inefficient than firm $j$ regarding the abatement technology), firm $i$ becomes interested in using more permits in production (to reduce its abatement needs). Hence, given $\gamma_{j}$, the higher $\gamma_{i}$, the more (less) permits firm $i$ buys (sells).

${ }^{15}$ Later on, when solving the first stage, we will show that $q^{*} \geq \underline{q}>\gamma_{i} \frac{2-S}{3 \gamma_{i}+5}$. Accordingly, after the first stage is solved, it will be possible to prove that in equilibrium we always have $q^{*}>\gamma_{i} a_{i}^{*}$.

${ }^{16}$ If we had assumed Cournot competition on both markets the qualitative result in Proposition 1 would still hold since firm $j$ would have a reaction function capturing its desire of rising the rival's cost just like firm $i$, and the resulting equilibrium would imply marginal abatement costs lower than the price of permits for both firms.
} 
than $\mathrm{MAC}_{i}$. In this context, permits are relatively cheap and firm $i$ would be interested in buying more permits from firm $j$. However, in this case, firm $i$ cannot buy more permits since $x_{i}^{*}=S-\alpha S$.

The following figure depicts $\mathrm{MAC}_{i}$ as a function of $q$ when firm $i$ optimally chooses the quantity of permits to buy/sell (accounting for the equilibrium in the last stage of the game). ${ }^{17}$ This relationship is illustrated for three different values of $\gamma_{i}$. The full line represents the $45^{\circ}$ degree line, the thickest dashed line represents the equilibrium relationship between $q$ and the $\mathrm{MAC}_{i}$ for $\gamma_{i}=1$. The thin dashed line represents the equilibrium relationship between $q$ and the $\mathrm{MAC}_{i}$ for $\gamma_{i}=3$. Finally the remaining dashed line represents the case of $\gamma_{i}=2$.

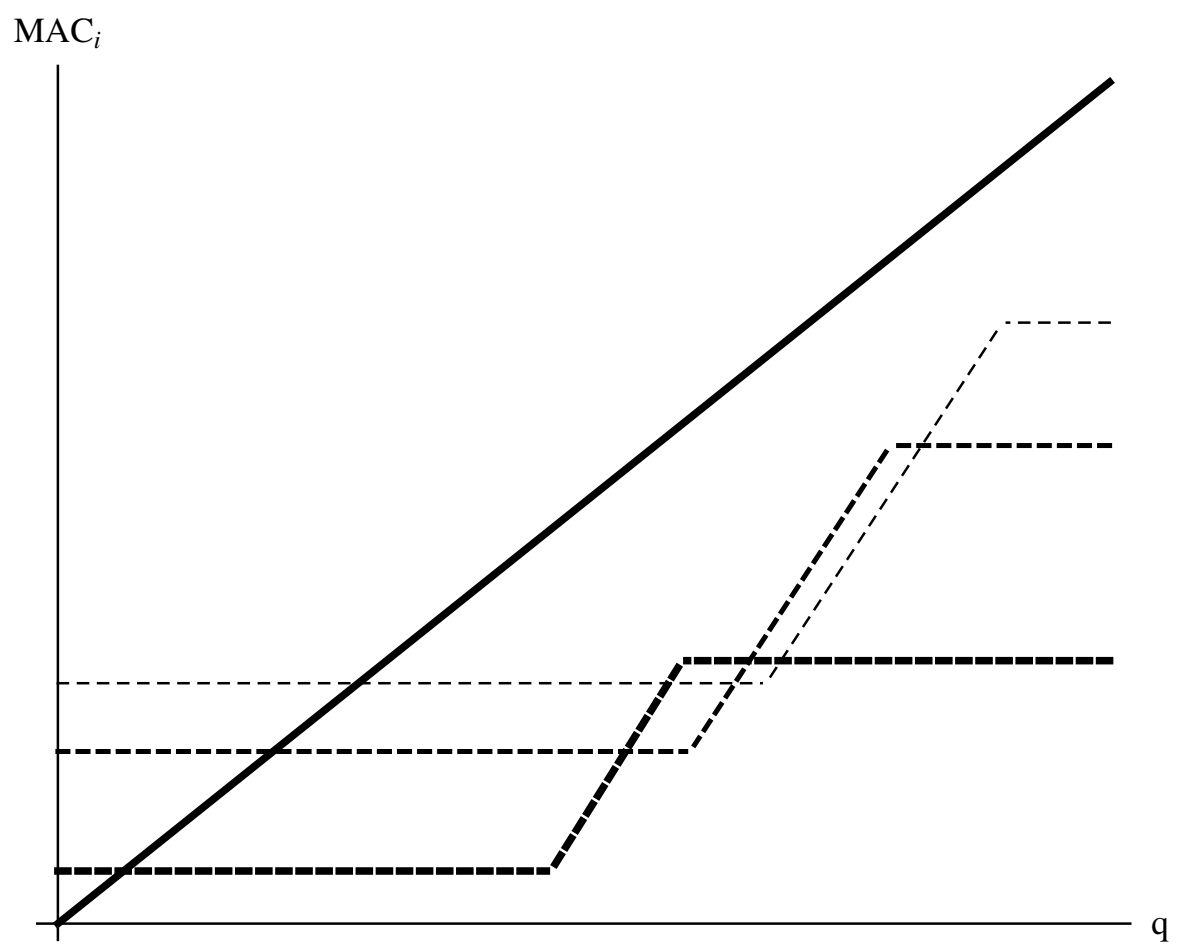

Figure 2: $\mathrm{q}$ and $\mathrm{MAC}_{i}$ for different $\gamma_{i}$-values.

\subsection{Permits price setting decision}

In the first stage, firm $j$ quotes the price of permits $(q)$ that solves the following optimization problem

$$
\max _{q \geq 0} \Pi_{j}\left(q, x_{i}^{*}(q), y_{i}^{*}\left(x_{i}^{*}(q)\right), y_{j}^{*}\left(x_{i}^{*}(q)\right)\right)
$$

\footnotetext{
${ }^{17}$ Recall that firm $i$ takes $q$ as given in the second stage of the game.
} 
When deciding $q$, firm $j$ anticipates firm $i$ 's demand of permits as well as the subsequent equilibrium of the Cournot interaction in the output market. Accordingly, firm $j$ anticipates that (i) when it quotes $q<q$, a corner solution arises with $x_{i}^{*}(q)=S-\alpha S$; (ii) when it quotes $q>\bar{q}$, a different corner solution arises with $x_{i}^{*}(q)=-\alpha S$; and, finally (iii) when $\underline{q}<q<\bar{q}$ the demand for permits is given by (10).

In the first case, the price of permits is so low that firm $i$ buys all the permits initially allocated to firm $j$. Since in that case, permits demand is insensitive to price variations and firm $j$ is selling permits, it fixes

$$
q^{*}=\underline{q}=\frac{(6-9 S) \gamma_{i}^{2}+(14-19 S) \gamma_{i}+4}{\left(3 \gamma_{i}+5\right)^{2}}>0 .
$$

In case (ii), the price of permits is so high, that firm $i$ sells all its initial stock of permits. The supply of permits by firm $i$ in this case is insensitive to price variations (corner solution) and firm $j$ takes advantage of being a price-maker to set the lowest possible price, with

$$
q^{*}=\bar{q}=\frac{\left(\gamma_{i}+2\right)\left(3 \gamma_{i}+1\right)(2-S)}{\left(3 \gamma_{i}+5\right)^{2}}>0 .
$$

Finally, in case (iii) the permits demand (10) is sensitive to price variations. In this case, the second order condition

$$
\frac{\partial^{2} \Pi_{j}\left(q, x_{i}^{*}(q), y_{i}^{*}\left(x_{i}^{*}(q)\right), y_{j}^{*}\left(x_{i}^{*}(q)\right)\right)}{\partial q^{2}}<0
$$

always holds and the closed form solution for $q^{*}$ can be directly obtained from the first order conditions associated to problem (11),

$$
\frac{\partial \Pi_{j}\left(q, x_{i}^{*}(q), y_{i}^{*}\left(x_{i}^{*}(q)\right), y_{j}^{*}\left(x_{i}^{*}(q)\right)\right)}{\partial q}=0,
$$

yielding $q^{*}=q^{*, i n t}$, with:

$$
q^{*, i n t}=\frac{54 \gamma_{i}^{4}+294 \gamma_{i}^{3}+498 \gamma_{i}^{2}+274 \gamma_{i}+32-\left[4\left(6 \gamma_{i}+3 \gamma_{i}^{2}-1\right)^{2} \alpha+27 \gamma_{i}^{4}+183 \gamma_{i}^{3}+381 \gamma_{i}^{2}+245 \gamma_{i}-4\right] S}{3\left(\gamma_{i}+3\right)\left(3 \gamma_{i}+1\right)\left(3 \gamma_{i}+5\right)^{2}} .
$$

The following lemma summarizes firm $j$ 's optimal choice in the first stage.

Lemma 5 In the first stage of the game, the equilibrium price of permits is given by

$$
q^{*}=\left\{\begin{array}{cll}
\underline{q} & \text { if } & S<\underline{S} \\
q^{*, i n t} & \text { if } & S \geq \underline{S}
\end{array},\right.
$$

with $\underline{S}=\frac{2-2 \gamma_{i}}{2-\gamma_{i}\left(25+9 \gamma_{i}\right)+2 \alpha\left(-1+3 \gamma_{i}\left(2+\gamma_{i}\right)\right)}$. 
Proof. See the Appendix.

Lemma 2 shows that when the stock of available permits is very low $(S<\underline{S})$, the extent to which firm $j$ is interested in exploiting a "rival-cost-rising strategy" is rather limited. In fact, firm $i$ has a higher willingness to pay since it is less efficient in the abatement technology and, with few permits available, firm $j$ can and will make more profits in the permits market (selling all its inital stock of permits) rather than using the permits price as a device to rise the rival's costs on the product market.

Differently, when the stock of available permits is sufficiently large, $S>\underline{S}$, in equilibrium, firm $j$ optimally balances the profit opportunities in the upstream and the downstream markets by equating the marginal profit of selling an additional permit (the opportunity cost, when both permits and output markets are taken into consideration) with the marginal benefit of retaining it.

Finally, it is to be noted that firm $j$ does never find profitable to buy all the permiys from firm $i$ (the other boundary solution, in which $x_{i}^{*}=-\alpha S$ ). The intuition for this result is quite straightforward once the fact that firm $j$ is more efficient in the abatement technology is taken into account.

Proposition 6 Firm $j$ always marks-up the price of permits fixing a $q^{*}$ higher than its equilibrium marginal abatement cost, $M A C_{j}\left(a_{j}^{*}\right)$.

Proof. See the Appendix.

Proposition 2 shows that for any initial stock of permits such that $0<S<\frac{2}{3}$, the equilibrium price of permits is always larger than the equilibrium marginal abatement cost. When $S<\underline{S}$, the intuition for the result in Proposition 2 is quite simple: since firm $j$ chooses to sell all its permits, it marks-up the price in order to make profit in the permits market. When $S \geq \underline{S}$, the intuition is more complex. In that case, the optimization condition associated with the closed form solution for $q^{*}(12)$ can be written as follows:

$$
q^{*}-\gamma_{j} a_{j}^{*}=\frac{x_{i}^{*}(q)}{-\frac{\partial x_{i}^{*}(q)}{\partial q}}+\frac{1}{-\frac{\partial x_{i}^{*}(q)}{\partial q}}\left[y_{j}^{*}\left(x_{i}^{*}(q)\right) \frac{d p^{*}\left(x_{i}^{*}(q)\right)}{d q}+\left(p-\gamma_{j} a_{j}^{*}\right) \frac{d y_{j}^{*}\left(x_{i}^{*}(q)\right)}{d q}\right],
$$

where $\gamma_{j}=1$.

The condition (13) shows that in the interior equilibrium, the difference between $q^{*}$ and $j$ 's marginal abatement cost can be decomposed in two terms. The first determinant of the gap between the two is associated with the market power of firm $j$ in the permits market and it corresponds to $\frac{x_{i}^{*}(q)}{-\frac{\partial x_{i}^{*}(q)}{\partial q}}$ in condition (13). Focusing exclusively on this effect, condition (13) implies that, everything else the same, when firm $j$ is a net-seller of permits $\left(x_{i}^{*}<0\right)$, it enjoys a positive mark-up over its MAC as a result of its market power in the permits market. 
Differently, when firm $j$ is a net-buyer of permits $\left(x_{i}^{*}>0\right)$, firm $j$ marks-down the price of permits (benefiting from a price discount).

The second determinant of the difference between the price of permits $q^{*}$ and $j$ 's MAC corresponds to the term

$$
\frac{1}{-\frac{\partial x_{i}^{*}(q)}{\partial q}}\left[y_{j}^{*}\left(x_{i}^{*}(q)\right) \frac{d p^{*}\left(x_{i}^{*}(q)\right)}{d q}+\left(p-\gamma_{j} a_{j}^{*}\right) \frac{d y_{j}^{*}\left(x_{i}^{*}(q)\right)}{d q}\right] .
$$

This term is always positive for $\gamma_{i}>1$, since $-\frac{\partial x_{i}^{*}(q)}{\partial q}<0, \frac{d p^{*}\left(x_{i}^{*}(q)\right)}{d q}<0$ and $\frac{d y_{j}^{*}\left(x_{i}^{*}(q)\right)}{d q}<0$. This second determinant of the price gap between firm $j$ 's marginal abatement cost and the equilibrium price of permits can be thought as a "cost-rising strategy effect". This effect on permits price is further aggravated by the behavior of firm $i$ that we discussed in the second stage. Anticipating the followers' behavior and regardless its position in the permits market (seller/buyer), firm $j$ sets a higher price of permits as an attempt to make firm $i^{\prime} s$ cost-rising strategy less effective (see equation (14)).

When firm $j$ is a net seller of permits, the two effects reinforce each other and as expected we have $q^{*}>M A C_{j}$. When firm $j$ is a net buyer of permits, the two effects move in opposite directions. Proposition 2 shows that in our Cournot set-up, the second effect is dominant. Hence, even when firm $j$ is a net-buyer of permits, in equilibrium, the firm chooses a price of permits above its equilibrium marginal abatement cost. By setting a higher price of permits, firm $j$ is able to increase the amount of permits sold by firm $i$ in equilibrium. This, in turn, reduces firm $i^{\prime}$ s permits holdings and increases its abatement needs. As a result firm $i$ becomes less competitive in the output market, to the benefit of firm $j$.

\section{Without downstream strategic interaction}

Herein we develop a benchmark case in which the two firms interacting in the permits market do not strategically interact in a downstream market. To this end, we assume that there are two independent monopolies in the market for final goods. Let us split the market in a way that each firm faces half of total demand, i.e. $y_{k}=\frac{1}{2}\left(A-p_{k}\right)$ for $k=i, j$. Then, the inverse demand function writes:

$$
p_{k}=A-2 y_{k} \quad \text { with } \quad k=i, j .
$$

To make the analysis comparable with the previous sections, we set $A=1$ and production costs equal to zero. To keep computations as simple as possible, we set $\gamma_{j}=1$ as above, and also assume $S<\frac{1}{4}$, where the threshold $\frac{1}{4}$ corresponds to the monopoly quantity with zero production costs and no environmental regulation.

In this case, total profits are defined as follows: 


$$
\begin{aligned}
\Pi_{i}^{M}\left(q, x_{i}, y_{i}, y_{j}\right) & =y_{i} p\left(y_{i}\right)-q x_{i}-\frac{\gamma_{i}}{2}\left(y_{i}-x_{i}-\alpha S\right)^{2}, \\
\Pi_{j}^{M}\left(q, x_{i}, y_{i}, y_{j}\right) & =y_{j} p\left(y_{j}\right)+q x_{i}-\frac{1}{2}\left[y_{j}+x_{i}-(1-\alpha) S\right]^{2},
\end{aligned}
$$

Under the previous assumptions each firm is a monopolist facing its own demand (15). The third stage results in the following monopoly quantities:

$$
\begin{aligned}
y_{j}^{M O N} & =\frac{1+(1-\alpha) S-x_{i}}{4+\gamma_{j}} ; \\
y_{i}^{M O N} & =\frac{1+\gamma_{i}\left(\alpha S+x_{i}\right)}{4+\gamma_{i}} .
\end{aligned}
$$

In the second stage the follower in the market for permits (firm $i$ ) chooses the amount of permits to buy/sell, which is summarized in the following demand function:

$$
\hat{x}_{i}(q)=\left\{\begin{array}{lr}
-S \alpha & \text { if } q \geq \frac{\gamma_{i}}{4+\gamma_{i}} \\
\frac{\gamma_{i}-4 S \alpha \gamma_{i}-q\left(4+\gamma_{i}\right)}{4 \gamma_{i}} & \text { if } \frac{\gamma_{i}-4 S \gamma_{i}}{4+\gamma_{i}}<q<\frac{\gamma_{i}}{4+\gamma_{i}} \\
(1-\alpha) S & \text { if } q \leq \frac{\gamma_{i}-4 S \gamma_{i}}{4+\gamma_{i}}
\end{array}\right.
$$

Notice that $\hat{x}_{i}(q)>0$ if and only if $q<\frac{\gamma_{i}-4 S \alpha \gamma_{i}}{4+\gamma_{i}}$ and that the SOC is always verified: $\frac{\partial^{2} \Pi_{i}^{M}}{\partial x_{i}^{2}}=-\frac{4 \gamma_{i}}{4+\gamma_{i}}<0$.

From (19), it also follows that $\frac{\gamma_{i}-4 S \gamma_{i}}{4+\gamma_{i}}>0$, for $S<\frac{1}{4}$. Accordingly, when the price of permits is zero ${ }^{18}$, we would always have a boundary solution in the second stage, with firm $i$ buying all the permits from firm $j$, i.e., $\hat{x}_{i}(q)=(1-\alpha) S$.

When the solution is interior, firm $i$ demands permits up to the point in which its marginal abatement cost equals the price of permits. Indeed, the FOC for firm $i$ in the second stage is:

$$
\frac{d \Pi_{i}^{M}\left(y_{i}^{*}\left(x_{i}\right), x_{i}\right)}{d x_{i}}=\frac{\partial \Pi_{i}^{M}\left(., x_{i}\right)}{\partial x_{i}}+\frac{\partial \Pi_{i}^{M}\left(y_{i}^{*}\left(x_{i}\right), .\right)}{\partial y_{i}} \frac{\partial y_{i}^{*}\left(x_{i}\right)}{\partial x_{i}}=0
$$

where it is easy to show that the second term is zero (using the FOC in the third stage and the Envelope theorem), i.e.:

$$
\frac{d \Pi_{i}^{M}\left(y_{i}^{*}\left(x_{i}\right), x_{i}\right)}{d x_{i}}=\frac{\partial \Pi_{i}^{M}\left(., x_{i}\right)}{\partial x_{i}}=0,
$$

where $\frac{\partial \Pi_{i}\left(., x_{i}\right)}{\partial x_{i}}=M A C_{i}\left(a_{i}^{*}\right)-q=0$. Then,

$$
q=\gamma_{i}\left[y_{i}^{*}\left(x_{i}\right)-\alpha S-x_{i}\right]=M A C_{i}\left(a_{i}^{*}\right) .
$$

\footnotetext{
${ }^{18}$ Or even negative, if that would be possible.
} 
The previous result simply shows that, without rivalry in the market for the final good, firm $i$ behaves as a conventional price-taking firm since it has no incentive to play a rival's costraising strategy. Without strategic interaction in a downstream market our model converges with the seminal paper of Montgomery (1972): the firm without market power in the permits market abates pollution up to the point where its marginal abatement cost equals the price of permits.

In the first stage, the leader (firm $j$ ) chooses the price of permits summarized in the following FOC:

$$
\frac{d \Pi_{j}^{M}\left(y_{j}^{*}\left(x_{i}^{*}(q)\right), x_{i}^{*}(q), q\right)}{d q}=0,
$$

or equivalently,

$$
\frac{\partial \Pi_{j}^{M}\left(y_{j}^{*}\left(x_{i}^{*}(q)\right), . . .\right)}{\partial y_{j}} \frac{\partial y_{j}^{*}\left(x_{i}^{*}(q)\right)}{\partial x_{i}} \frac{\partial x_{i}^{*}(q)}{\partial q}+\frac{\partial \Pi_{j}^{M}\left(., x_{i}^{*}(q), .\right)}{\partial x_{i}} \frac{\partial x_{i}^{*}(q)}{\partial q}+\frac{\partial \Pi_{j}^{M}(., ., q)}{\partial q}=0
$$

where the first term is zero (using the FOC in the third stage and the Envelope Theorem). Hence, at equilibrium:

$$
\frac{d \Pi_{j}^{M}\left(y_{j}^{*}\left(x_{i}^{*}(q)\right), x_{i}^{*}(q), q\right)}{d q}=\frac{\partial \Pi_{j}^{M}\left(., x_{i}^{*}(q), .\right)}{\partial x_{i}} \frac{\partial x_{i}^{*}(q)}{\partial q}+\frac{\partial \Pi_{j}^{M}(., ., q)}{\partial q}=0
$$

Condition (23) shows that in the context of two independent downstream monopolies, the price-making firm in the permits market is able to manipulate the price of permits to derive profits from selling/buying permits. ${ }^{19}$ Since $\frac{\partial \Pi_{j}^{M}(.,, q)}{\partial q}=x_{i}$, if the leader is a seller of permits $\left(x_{i}>0\right)$ it will fix a price of permits such that $q^{*}>M A C_{j}\left(a_{j}^{*}\right)$. Instead, if it is a buyer of permits $\left(x_{i}<0\right)$ it fixes a price such that $q^{*}<M A C_{j}\left(a_{j}^{*}\right)$.

The explicit solution for the price of permits chosen by the leader is:

$$
q^{\star}=\left\{\begin{array}{lcc}
\frac{(1-4 S) \gamma_{i}}{4+\gamma_{i}} & \text { if } \quad \alpha \geq \frac{1-\gamma_{i}+10 S \gamma_{i}}{5 S \gamma_{i}} \\
\frac{\gamma_{i}\left(8(1-2 S)+(7-4 S(1+5 \alpha)) \gamma_{i}\right)}{\left(4+\gamma_{i}\right)\left(4+11 \gamma_{i}\right)} & \text { if } \quad \alpha<\frac{1-\gamma_{i}+10 S \gamma_{i}}{5 S \gamma_{i}}
\end{array}\right.
$$

When $x_{i}^{*}<0$, which occurs when $\alpha>\frac{\gamma_{i}-\left(1-S\left(4+\gamma_{i}\right)\right)}{4 S \gamma_{i}+2 S\left(2+\gamma_{i}\right)}$, the leader is a net buyer of permits and therefore it fixes a price of permits that is lower than its marginal abatement cost. The opposite happens if the leader is a net seller of permits $\left(x_{i}^{*}>0\right)$. The previous result shows

\footnotetext{
${ }^{19}$ In condition (23), we have that $\frac{\partial \Pi_{j}^{M}\left(., x_{i}^{*}(q), .\right)}{\partial x_{i}} \frac{\partial x_{i}^{*}(q)}{\partial q}=-q+M A C_{j}\left(a_{j}\right)$. If the term $\frac{\partial \Pi_{j}^{M}(., ., q)}{\partial q}$ in $(23)$ was zero, then firm $j$ would set the price of permits such that $q=M A C_{j}\left(a_{j}\right)$, and the firm would not exploit any profit opportunities in the permits market. However, given firm $j$ 's price leadership, we have $\frac{\partial \Pi_{j}^{M}(., ., q)}{\partial q}=x_{i}$ and therefore, as long as there is trading in the permits market, firm $j$ is able to exploit profit opportunities in this market.
} 
that, without strategic interaction in the downstream market, our model produces the same results as in Hahn (1984).

The following figure shows the demand for permits of the follower $i$ (straight line) and the iso-profit curve of the leader $j$ when $S=0,2$ and $\alpha=1 / 3$. The full lines depict the case where $\gamma_{i}=2$ while the dashed lines depict the case where $\gamma_{i}=5$.

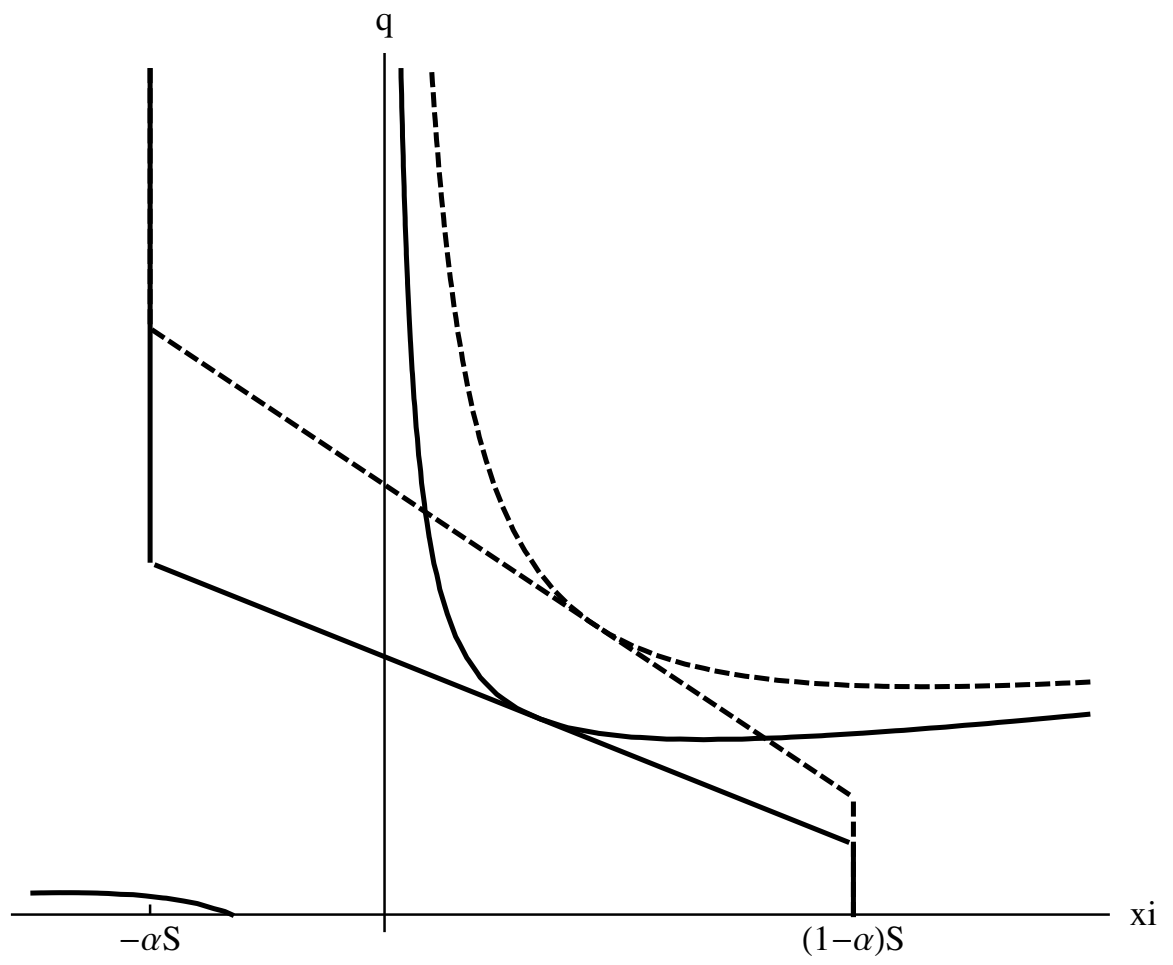

Figure 3: Optimal $q^{*}$-choice: interior solution.

The leader chooses the point in the follower's permits demand function that yields the highest profit. For the interior solutions, such optimal point $q^{*}$ occurs where the follower's demand function is tangent to the highest iso-profit curve.

In the previous section we have showed how the standard results of the previous literature no longer hold when considering strategic interaction in the final good market. In this section our results reinforce the idea that considering the structure of the downstream market is crucial since, putting aside strategic interaction in the downstream market, the model would produce the same predictions as in the previous literature (Montgomery, 1972; Hahn, 1984; and Eshel, 2005, among others). However, as soon as we account for the strategic interaction taking place in the output market, our analysis in section 3 shows that new aspects must be taken into account when explaining firms' behavior in the permits market. 


\section{Concluding remarks}

We have proposed a model of upstream-downstream competition, whose major features are: (i) the explicit consideration of the technological linkages between the permits market (upstream) and the output market (downstream); (ii) strategic interaction in the output market, with firms competing à la Cournot; and (iii) the existence of market power in the permits market, in which the most efficient firm is also assumed to move first in the permits market.

Besides market distortions associated with market power in the permits market (as in Hahn, 1985) and market distortions associated with the possibility of having a dominant firm adopting rival's cost-raising strategies (as in Misiolek and Elder, 1989; and Eshel, 2005), we show that strategic interaction in the output market may give raise to an additional source of market distortion. This market distortion is associated with the fact that a follower in the permits market (exerting some degree of market power in the output market) may adopt a rival's cost-raising strategy as well. The sole consideration of the latter provokes a change in Eshel's (2005) dominant firm framework: since now there is a strategic competitor in the output market, the dominant firm is now forced to mark-up the permit price even when it is a net buyer of permits.

\section{References}

[1] Amir, R. (2005). 'Supermodularity and Complementarity in Economics: An Elementary Survey', Southern Economic Journal, Vol. 71, No. 3, pp. 636-660.

[2] Boemare, C. and Quirion, P. (2002). 'Implementing greenhouse gas trading in Europe: lessons from economic literature and international experiences', Ecological Economics, Vol. 43, No. 2-3, pp. 213-230.

[3] Brown-Kruse, J., Elliot, S. R. and Godby R. (1995). 'Strategic manipulation of pollution permit markets: an experimental approach', McMaster University, Department of Economics Working Papers 1995-03.

[4] Chen Y. and Hobbs, B. F. (2005). 'An Oligopolistic Power Market Model With Tradable $N O_{X}$ Permits', IEEE Transactions on Power Systems, Vol. 20, No. 1, pp. 119-129.

[5] Eshel D. M. D. (2005). 'Optimal allocation of tradable pollution rights and market structures', Journal of Regulatory Economics, Vol. 28, No. 2, pp. 205-223.

[6] Fehr, N.-H. M. v. d. (1993). 'Tradable Emission Rights and Strategic Interaction', Environmental and Resource Economics, Vol. 3, No. 2, pp. 129-151. 
[7] Godby, R. (2002). 'Market power in laboratory emission permit markets', Environmental and Resource Economics, Vol. 23, No. 3, pp. 279-318.

[8] Hahn, R. (1985). 'Market power and transferable property rights', Quarterly Journal of Economics, Vol. 99, No. 4 pp.753-765.

[9] Houghton, J.T., Jenkinks, G.J. and Ephraums, J. J. (eds.) (1990), Climate change: The IPCC Scientific Assessment, Cambridge, MA,Cambridge University Press.

[10] Kolstad, J. and Wolak, F. (2008). 'Using emission permits prices to rise electricity prices: Evidence from the California electricity market', Harvard University, mimeo.

[11] Linares, P., Santos, J., Ventosa, M. and Lapiedra, L., (2006). 'Impacts of the European Emissions Trading Scheme Directive and Permit Assignment Methods on the Spanish Electricity Sector', The Energy Journal, Vol. 27, No. 1, pp. 79-98.

[12] Mestelman, S. and Muller, A. (1997). 'What Have We Learned From Emissions Trading Experiments?', McMaster University, McMaster Experimental Economics Laboratory Publications 1997-03.

[13] Misiolek, W. S. and Elder, H. W. (1989). 'Exclusionary manipulation of markets of pollution rights', Journal of Environmental Economics and Management, Vol. 16, No. 2, pp. 156-166.

[14] Montero, J.-P. (2002). 'Permits, Standards, and Technology Innovation', Journal of Environmental Economics and Management, Vol. 44, No. 1, pp. 23-44.

[15] Montero, J.-P. (2009). 'Market Power in Pollution Permit Markets', The Energy Journal, Vol. 30, Special Issue No. 2, pp. 115-142.

[16] Montgomery, D. W. (1972). 'Market in Licenses and Efficient Pollution Control Programs', Journal of Economic Theory, Vol. 5, No. 3, pp. 395-418.

[17] Ordover, J., Saloner, G. and Salop, S. (1990). 'Equilibrium Vertical Foreclosure', The American Economic Review, Vol. 80, No. 1, pp. 127-142.

[18] Salinger, M. (1988). 'Vertical Mergers and Market Foreclosure', The Quarterly Journal of Economics, Vol. 103, No. 2, pp. 345-356.

[19] Salop, S. C. and Scheffman, D. T. (1983). 'Raising rivals' costs', American Economic Review Papers and Proceedings, Vol. 73, No. 2, pp. 267-271. 
[20] Sartzetakis, E. S. (1997). 'Tradable Emission Permits Regulations in the Presence of Imperfectly Competitive Product Markets: Welfare Implications', Environmental and Resource Economics, Vol. 9, No. 1, pp. 65-81.

[21] Tietenberg T. H. (2006). Emission Permits: principles and practice, Washington D.C., Resources for the Future Press.

\section{Appendix}

\section{Proof of Lemma 1}

The demand of permits by firm $i$ in the second stage is given by:

$$
x_{i}^{*}(q)=\min \left\{(1-\alpha) S, \max \left\{-\alpha S, x_{i}^{*, i n t}(q)\right\}\right\} .
$$

The bondary solution $x_{i}^{*}(q)=\alpha S$ arises whenever the price of permits quoted by firm $j$ in the first stage is such that $q>\bar{q}=\frac{\left(\gamma_{i}+2\right)\left(3 \gamma_{i}+1\right)(2-S)}{\left(3 \gamma_{i}+5\right)^{2}}$. The threshold $\bar{q}$ is obtained from the condition $x_{i}^{*, i n t}(q)<-\alpha S$. Similarly, the corner solution in which $x_{i}^{*}(q)=(1-\alpha) S$ only arises when the price of permits quoted by firm $j$ in the first stage is such that $q<\underline{q}=$ $\frac{(6-9 S) \gamma_{i}^{2}+(14-19 S) \gamma_{i}+4}{\left(3 \gamma_{i}+5\right)^{2}}$, where the latter threshold is obtained by plugging (10) into condition $x_{i}^{*, i n t}(q)>(1-\alpha) S$.

\section{Proof of Proposition 1}

First, consider the case in which the equilibrium choice of $x_{i}$ corresponds to an interior solution. In this case, the following FOC

$$
\frac{\partial \Pi_{i}\left(x_{i}, y_{i}^{*}\left(x_{i}\right), y_{j}^{*}\left(x_{i}\right), q\right)}{\partial x_{i}}=0
$$

must hold, yielding:

$$
q=-\frac{\left(2 S-14 \gamma_{i}-2 x_{i}-2 S \alpha+7 S \gamma_{i}-6 \gamma^{2}+12 \gamma_{i} x_{i}+3 S \gamma_{i}^{2}+6 \gamma_{i}^{2} x_{i}+12 S \alpha \gamma_{i}+6 S \alpha \gamma_{i}^{2}-4\right)}{\left(3 \gamma_{i}+5\right)^{2}}
$$

Recall that, given our specification of firms' abatement technologies, the marginal abatement cost for firm $i$ is equal to:

$$
\gamma_{i} a_{i}=\gamma_{i}\left(-x_{i}+y_{i}-S \alpha\right) .
$$

Since in equilibrium, we have $y_{i}^{*}\left(x_{i}\right)=\frac{\left(3 \gamma_{i}+1\right)\left(x_{i}+S \alpha\right)+2-S}{3 \gamma_{i}+5}$, the gap between the price of permits and the marginal abatement cost of firm $i$ at equilibrium $\left(M A C_{i}\left(a_{i}^{*}\right)=\gamma_{i} a_{i}^{*}\right)$ is equal 
to:

$$
q-\gamma_{i}\left(-x_{i}+\frac{\left(3 \gamma_{i}+1\right)\left(x_{i}+S \alpha\right)+2-S}{3 \gamma_{i}+5}-S \alpha\right)
$$

Subtracting $\gamma_{i}\left(-x_{i}+\frac{\left(3 \gamma_{i}+1\right)\left(x_{i}+S \alpha\right)+2-S}{3 \gamma_{i}+5}-S \alpha\right)$ in both sides of $(24)$, we obtain:

$$
q-\gamma_{i} a_{i}^{*}=2\left(\gamma_{i}+1\right) \frac{-S+2+\left(3 \gamma_{i}+1\right)\left(x_{i}+S \alpha\right)}{\left(3 \gamma_{i}+5\right)^{2}},
$$

with $q-\gamma_{i} a_{i}^{*}>0$ since $S<\frac{2}{3}$ and $x_{i}$, when negative (firm $i$ is selling permits) must be smaller than $\alpha S$, which is the amount of permits initially allocated to firm $i$.

This shows that whenever an interior solution is reached in the second stage, we observe $q>\gamma_{i} a_{i}^{*}$.

Now we study corner solutions, considering first the case in which $x_{i}^{*}=-\alpha S$. For $x_{i}^{*}=$ $-\alpha S$, firms' equilibrium output levels are equal to: $y_{i}^{*}=\frac{(2-S)}{3 \gamma_{i}+5}$ and $y_{i}^{*}=\frac{2 S+\gamma_{i}+S \gamma_{i}+1}{3 \gamma_{i}+5}$. So the marginal abatement cost by firm $i$ is given by: $\gamma_{i}\left(-x_{i}^{*}+y_{i}^{*}-S \alpha\right)=\gamma_{i} \frac{2-S}{3 \gamma_{i}+5}$.

Whenever $q>\gamma_{i} \frac{2-S}{3 \gamma_{i}+5}$, we have $q>\gamma_{i} a_{i}^{*}$. Recall that the corner solution in which $x_{i}^{*}=-\alpha S$ arises for

$$
q>\frac{\left(\gamma_{i}+2\right)\left(3 \gamma_{i}+1\right)(2-S)}{\left(3 \gamma_{i}+5\right)^{2}}>\gamma_{i} \frac{2-S}{3 \gamma_{i}+5},
$$

which guarantees that at the corner solution $x_{i}^{*}=-\alpha S$, arising for $q>\bar{q}$, we always have $q>\gamma_{i} a_{i}^{*}$.

Finally, we need to study the case of the corner solution in which $x_{i}^{*}=(1-\alpha) S$ arising for $q<\underline{q}=\frac{(6-9 S) \gamma_{i}^{2}+(14-19 S) \gamma_{i}+4}{\left(3 \gamma_{i}+5\right)^{2}}$. For $x_{i}=(1-\alpha) S$, firms' equilibrium output levels are equal to: $y_{i}^{*}=\frac{3 S \gamma+2}{3 \gamma+5}$ and $y_{i}^{*}=\frac{(\gamma-S \gamma+1)}{3 \gamma+5}$ and the marginal abatement cost by firm $i$ is equal to $\gamma_{i}\left(-x_{i}^{*}+y_{i}^{*}-S \alpha\right)=\frac{2 \gamma_{i}-5 S \gamma_{i}}{3 \gamma_{i}+5}$. Accordingly, for $q>\frac{2 \gamma_{i}-5 S \gamma_{i}}{3 \gamma_{i}+5}$, we would observe $q>\gamma_{i} a_{i}^{*}$. Since $\frac{2 \gamma_{i}-5 S \gamma_{i}}{3 \gamma_{i}+5}<\underline{q}$ for $\gamma_{i}>1$ and $S>0$, it follows that for

$$
\frac{2 \gamma_{i}-5 S \gamma_{i}}{3 \gamma_{i}+5}<q<\frac{(6-9 S) \gamma_{i}^{2}+(14-19 S) \gamma_{i}+4}{\left(3 \gamma_{i}+5\right)^{2}}
$$

we have $q>\gamma_{i} a_{i}^{*}$. However, if $q<\frac{2 \gamma_{i}-5 S \gamma_{i}}{3 \gamma_{i}+5}$, we have that $q<\gamma_{i} a_{i}^{*}$ as stated in Proposition 1 .

\section{Proof of Lemma 2}

First, notice that firm $j$ ' objective function in the first stage is continuous and strictly concave in $q \cdot{ }^{20}$ Simple calculation show that for $\gamma_{i}>1$ and $S<\frac{2}{3}$, we always have that $q^{*, i n t}<\bar{q}$, therefore, the price of permits $\bar{q}$ is never an equilibrium, which means that firm $j$

\footnotetext{
${ }^{20}$ Recall that the firm $i$ 's equilibrium permits demand is continuous despite the possibility of corner solutions. we have therefore that $\frac{\partial^{2} \Pi_{j}\left(q, x_{i}^{*}(q), y_{i}^{*}\left(x_{i}^{*}(q)\right), y_{j}^{*}\left(x_{i}^{*}(q)\right)\right)}{\partial q^{2}}<0$ for all $q \in \mathbb{R}^{+}$.
} 
is never interested in manipulating upwards the price of permits to such an extent that firm $i$ would like to sell all its permits. In contrast, the lowest price boundary may be chosen by firm $j$, since $q^{*, i n t}<\underline{q}$ when

$$
0<S<\underline{S}=\frac{2-2 \gamma_{i}}{2-\gamma_{i}\left(25+9 \gamma_{i}\right)+2 \alpha\left(-1+3 \gamma_{i}\left(2+\gamma_{i}\right)\right)}<\frac{2}{3} .
$$

Accordingly, as stated in Lemma 2 if $S<\underline{S}$, firm $j$ sets the boundary price $q^{*}=\underline{q}$. Otherwise firm $j$ sets $q^{*}=q^{*, i n t}$.

\section{Proof of Proposition 2}

First, we prove that in the case of an interior solution, we always obtain that $q>$ $M A C_{j}\left(a_{j}^{*}\right)$, with $M A C_{j}\left(a_{j}^{*}\right)=\gamma_{j} a_{j}^{*}$, with $\gamma_{j}=1$. To this end, we substitute the expressions in the RHS (13) by the equilibrium values obtaining:

$$
\frac{\left(26 S-264 S \gamma_{i}^{3}-372 S \gamma_{i}^{2}-104 S \gamma_{i}-54 S \gamma_{i}^{4}\right) \alpha+\Omega}{3\left(3 \gamma_{i}+5\right)^{2}\left(3 \gamma_{i}^{2}+10 \gamma_{i}+3\right)},
$$

with $\Omega$ given by

$$
\left(27 \gamma_{i}^{4}+153 \gamma_{i}^{3}+275 \gamma_{i}^{2}+147 \gamma_{i}-26\right) S+27 \gamma_{i}^{4}+126 \gamma_{i}^{3}+164 \gamma_{i}^{2}+50 \gamma_{i}+17
$$

Setting the previous expression equal to zero, so that $q$ would be equal to $a_{j}^{*}$ and solving for $\alpha$, we obtain that

$$
\alpha=\frac{\left(-26 S+50 \gamma_{i}+147 S \gamma_{i}+164 \gamma_{i}^{2}+126 \gamma_{i}^{3}+27 \gamma_{i}^{4}+275 S \gamma_{i}^{2}+153 S \gamma_{i}^{3}+27 S \gamma_{i}^{4}+17\right)}{-26 S+104 S \gamma_{i}+372 S \gamma_{i}^{2}+264 S \gamma_{i}^{3}+54 S \gamma_{i}^{4}}
$$

Since $\gamma_{i}>1$, the ratio in the previous expression is always positive and it can also be shown that the numerator is always larger than the denominator for $\gamma_{i}>1$ and $S<\frac{2}{3}$. This amounts to say that the $\alpha$-value that sets the RHS of (13) equal to zero is always larger than 1.

Differentiating (25) with respect to $\alpha$, we obtain that such derivative is negative. Accordingly, when $\alpha \in(0,1)$, we have that the RHS of $(13)$ is positive and therefore in the interior equilibrium, we have that $q^{*}>\gamma_{j} a_{j}^{*}$.

In the case of the corner solution that can also constitute an equilibrium in the first stage, we can prove that $q^{*}>\gamma_{j} a_{j}^{*}$ by showing that $\underline{q}>\gamma_{j} a_{j}^{*}$, when $x_{i}^{*}=(1-\alpha) S$. For this corner solution, we have $a_{j}^{*}=y_{j}^{*}=\frac{\gamma_{i}-S \gamma_{i}+1}{3 \gamma_{i}+5}$ and therefore it is enough to show that $\underline{q}>\frac{\gamma_{i}-S \gamma_{i}+1}{3 \gamma_{i}+5}$. Solving this inequality for $S$, we obtain:

$$
S<\frac{1}{2} \frac{6 \gamma_{i}+3 \gamma_{i}^{2}-1}{\gamma_{i}\left(3 \gamma_{i}+7\right)}
$$


Comparing the critical value of $S$ in (26) with the value of $\underline{S}$, we obtain that, for $\gamma_{i}>1$ and $0<\alpha<1$, the following inequality always holds $\underline{S}<\frac{1}{2} \frac{6 \gamma_{i}+3 \gamma_{i}^{2}-1}{\gamma_{i}\left(3 \gamma_{i}+7\right)}$. Therefore, whenever a corner solution arises, condition (26) is always verified and $q^{*}>\gamma_{j} a_{j}^{*}$ also in the case of the corner solution. 